\title{
Low-Profile Folded-Coupling Planar Inverted-F Antenna for 2.4/5 GHz WLAN Communications
}

\author{
Hung-Yu Li, ${ }^{1}$ Chun-Cheng Lin, ${ }^{2}$ Tsai-Ku Lin, ${ }^{1}$ and Chih-Yu Huang ${ }^{3}$ \\ ${ }^{1}$ Department of Physics, National Kaohsiung Normal University, Kaohsiung 802, Taiwan \\ ${ }^{2}$ Department of Mathematic and Physical Sciences, R.O.C. Air Force Academy, Kaohsiung 820, Taiwan \\ ${ }^{3}$ Department of Electronic Engineering, National Kaohsiung Normal University, Kaohsiung 802, Taiwan
}

Correspondence should be addressed to Chun-Cheng Lin; cclincafa@gmail.com

Received 4 May 2014; Accepted 15 June 2014; Published 26 June 2014

Academic Editor: Yingsong Li

Copyright (C) 2014 Hung-Yu Li et al. This is an open access article distributed under the Creative Commons Attribution License, which permits unrestricted use, distribution, and reproduction in any medium, provided the original work is properly cited.

A dual-band folded-coupling planar inverted-F antenna (FC-PIFA) is presented in this paper. By using the folded-coupling technique, the proposed antenna provides two distinct impedance bandwidths of $159 \mathrm{MHz}$ (about $6.5 \%$ centered at $2.45 \mathrm{GHz}$ ) and $1512 \mathrm{MHz}$ (about $27.5 \%$ centered at $5.5 \mathrm{GHz}$ ), which cover the required bandwidths for the $2.4 / 5 \mathrm{GHz}$ wireless local area network (WLAN) communications. Moreover, the antenna shows a low profile of $5 \mathrm{~mm}$ and a small length of $20.5 \mathrm{~mm}$ in radiating area, making it easy to be installed in the casing of wireless handheld devices and laptops. Details of the design procedures and experimental results are discussed.

\section{Introduction}

In wireless communication industry, planar inverted-F antenna (PIFA) is the most significant radiating elements owing to its compact size, multifrequency characteristic, and good compatibility to be integrated into mobile terminals and laptop computers. Recently, different types of PIFAs have been reported in many literatures for the growing demands of wireless local area network (WLAN) operations. An internal PIFA with modified radiating strips and appropriate feeding and shorting positions was published for $2.4 / 5 \mathrm{GHz}$ WLAN applications [1]. To overcome the narrow bandwidth property of conventional PIFAs, a coupled-fed PIFA with a band-notching slit was investigated [2]. By inserting a J-shaped slot and a meandering line on the conducting patch, the PIFA operates at WLAN and Worldwide Interoperability for Microwave Access (WiMAX) applications [3]. With embedding an $\mathrm{F}$ - and $\mathrm{T}$-shaped slot on the radiating structure and using a trapezoidal feeding plate, three resonant modes were generated and impedance bandwidth of the PIFA was enhanced [4]. By using two orthogonal radiators instead of a planar structure, the wideband characteristic is achieved by generating additional resonant frequency through a grounded strip [5]. However, these PIFAs still have high profiles or occupy large radiating areas.

In this paper, we propose a dual-band folded-coupling planar inverted-F antenna (FC-PIFA) for IEEE 802.11a $(2400-2480 \mathrm{MHz})$ and IEEE $802.11 \mathrm{~b} / \mathrm{g}(5150-5825 \mathrm{MHz})$ standards. We combine the concepts of a microstrip-coupled feeding line [6] and nearby conducting elements [7] and further represent a novel folded-coupling technique. By introducing this technique, the electromagnetic coupling effect generates an additional resonant mode to achieve wideband performance. The double-side configuration also decreases the profile and radiating area $(5 \mathrm{~mm} \times 20.5 \mathrm{~mm})$ of the proposed antenna, which is easier to be embedded as an internal antenna in narrow space within the casing of a portable wireless device, such as a laptop or smart phone. Moreover, its simple geometry provides an easy fabrication and a good radiating performance.

Details of the experimental results, including measurements and simulations, of the constructed prototype are discussed. Effects of the parameters of the folded-coupling region on the impedance bandwidth and surface current 


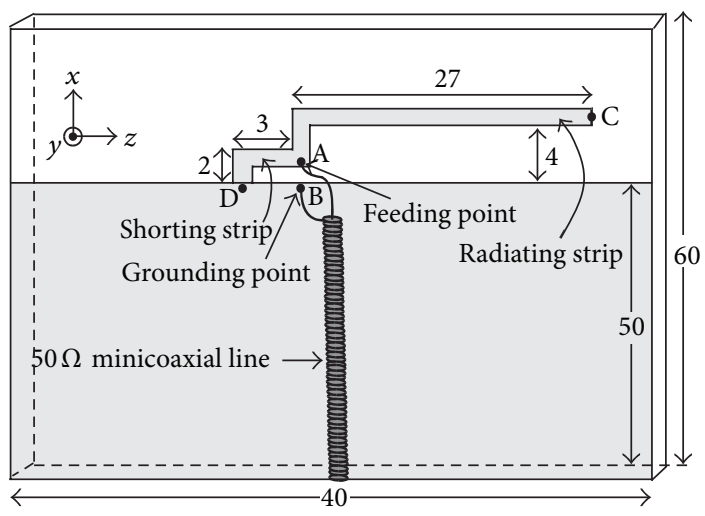

(a)

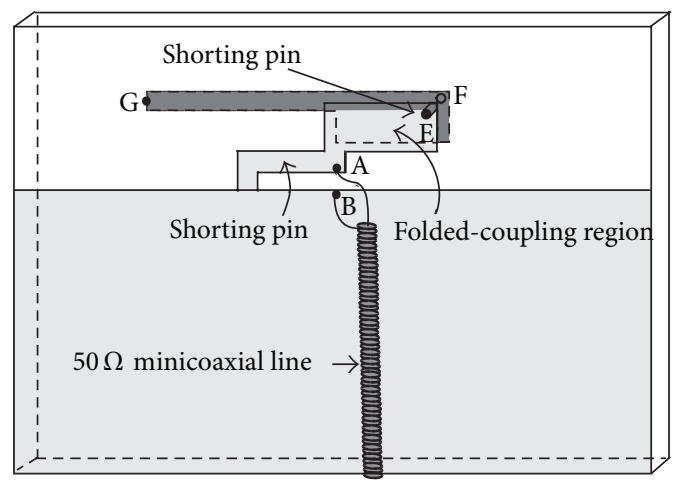

(b)

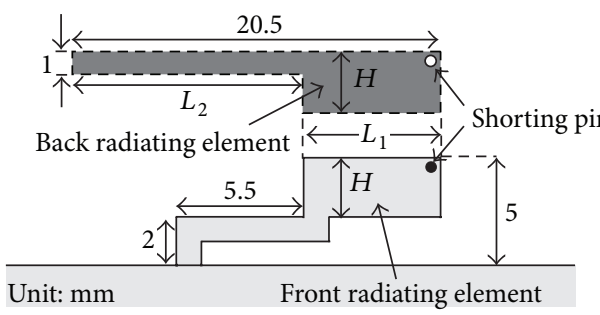

(c)

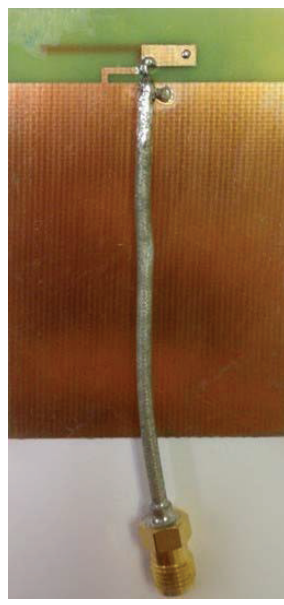

(d)

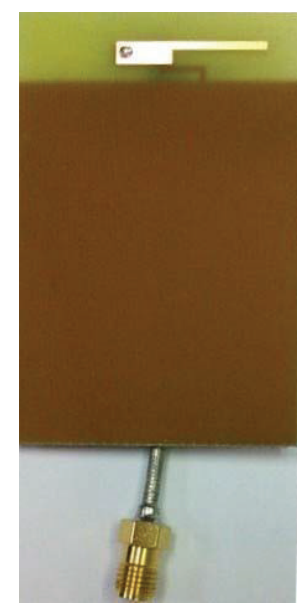

(e)

FIGURE 1: Geometry of (a) the conventional PIFA (reference antenna), (b) the proposed dual-band FC-PIFA for WLAN communications, and (c) the parameters of the folded-coupling region in (b); photograph of proposed FC-PIFA for (d) the front side and (e) the back side.

distributions are also analyzed. Furthermore, the radiating performance of the proposed antenna, including radiation patterns and peak gain values, are described.

\section{Antenna Design Concepts and Experimental Procedures}

Firstly, the design concepts of the antenna are investigated. Figures 1(a) and 1(b) show the constructions of the conventional folded planar inverted-F antenna (PIFA, denoted as reference antenna) and the proposed FC-PIFA, respectively. Both antennas are printed on FR4 substrates (dimensions of $60 \mathrm{~mm} \times 40 \mathrm{~mm}$, thickness of $0.8 \mathrm{~mm}$, and relative permittivity of 4.4). The antenna in Figure 1 (a) is fed by a $50 \Omega$ minicoaxial line, with its central conductor connected to point $\mathrm{A}$ (the feeding point) and its outer ground sheath connected to point B (the grounding point). All strip widths of the reference antenna are set as $1 \mathrm{~mm}$. The main radiating strip is from point $\mathrm{A}$ to $\mathrm{C}$ and the shorting strip is from point $\mathrm{A}$ to $\mathrm{D}$. The bending structure is for the purpose of a lower profile. However, its frequency ratio and bandwidth is insufficient for IEEE $802.11 \mathrm{~b} / \mathrm{g}(5150-5825 \mathrm{MHz})$ standards. Results are presented in the next section.

Hence, a folded-coupling technique is suggested. The antenna in Figure 1(b) is also fed by a $50 \Omega$ minicoaxial line, with its central conductor connected to point A (the feeding 


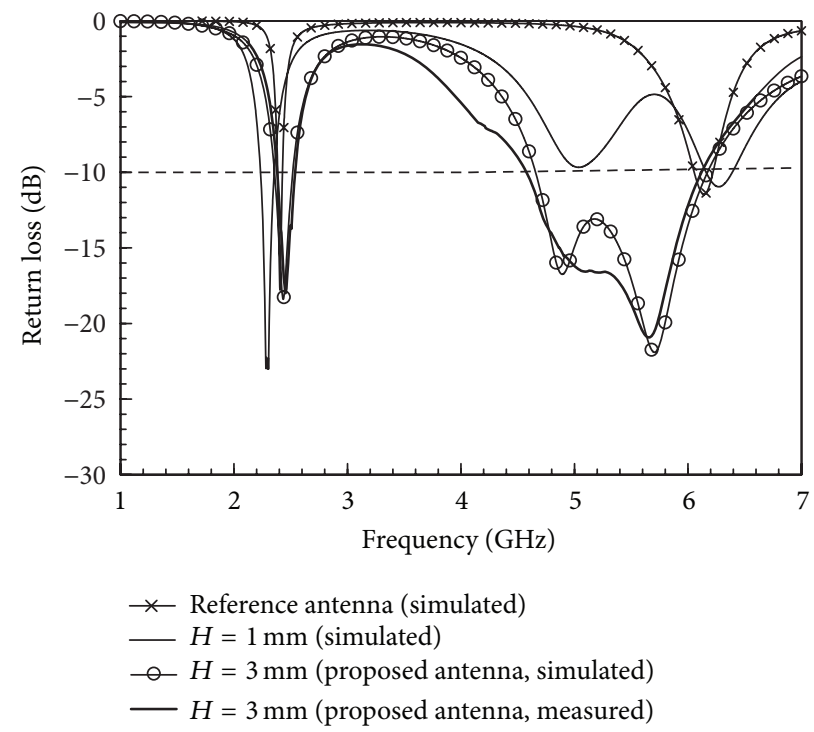

FIgURE 2: Simulated and measured return loss versus frequency for various $H ; L_{1}=7.5 \mathrm{~mm}$ and $L_{2}=13 \mathrm{~mm}$.

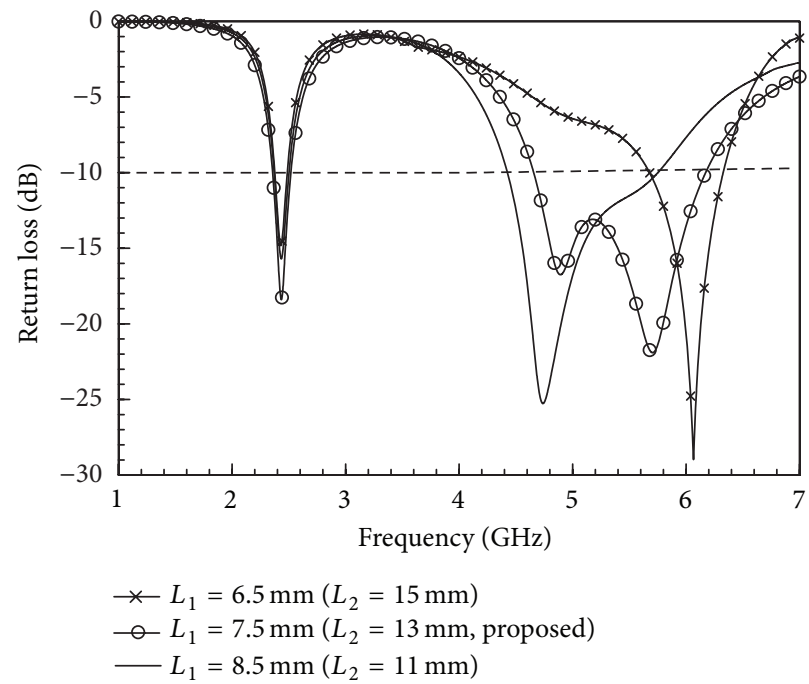

Figure 3: Simulated return loss versus frequency for various $L_{1} ; 2 L_{1}+L_{2}$ is fixed as $28 \mathrm{~mm}$ and $H=3 \mathrm{~mm}$.

point) and the outer ground sheath connected to point $\mathrm{B}$ (the grounding point). The front-side radiating strip is coincided with a portion of the back-side strip via a shorting pin for mutual coupling (point $\mathrm{A} \rightarrow \mathrm{E} \rightarrow \mathrm{F} \rightarrow \mathrm{G}$ ). The shorting pin enables the conventional PIFA transfigure to a FC-PIFA. With suitable size of the folded-coupling region, the electromagnetic coupling is generated, which introduces a new resonance mode around $5 \mathrm{GHz}$. The strip widths of the proposed antenna are set as $1 \mathrm{~mm}$ except the folded-coupling region in Figure 1(c), which is denoted as $H$. Furthermore, the foldedcoupling region contributes a large capacitance whereas the shorting strip is used for inductive tuning. Thus, good impedance matching for IEEE $802.11 \mathrm{a}(2400-2480 \mathrm{MHz})$ and IEEE $802.11 \mathrm{~b} / \mathrm{g}(5150-5825 \mathrm{MHz})$ standards can be easily achieved by adjusting the length of the shorting strip. Results are also presented in the next section. Figures 1(d) and 1(e) illustrate the photographs of the proposed FC-PIFA for the front and back side, respectively. In this work, the simulations were calculated with Ansoft HFSS and the measurements were obtained with an R\&S ZVB 40 vector network analyzer. The radiation patterns and gain values were measured in the far-field anechoic chamber.

\section{Results and Discussions}

Then, the experimental results of the antenna are investigated and discussed in this section. Figure 2 shows the simulated and measured return loss for the reference antenna and the proposed FC-PIFA with $H=1$ and $3 \mathrm{~mm}$, respectively. Although the reference antenna has dual resonant frequencies, it is unsuitable for dual-band operation of $2.4 / 5 \mathrm{GHz}$ due to its inadequate frequency ratio and narrow bandwidth 


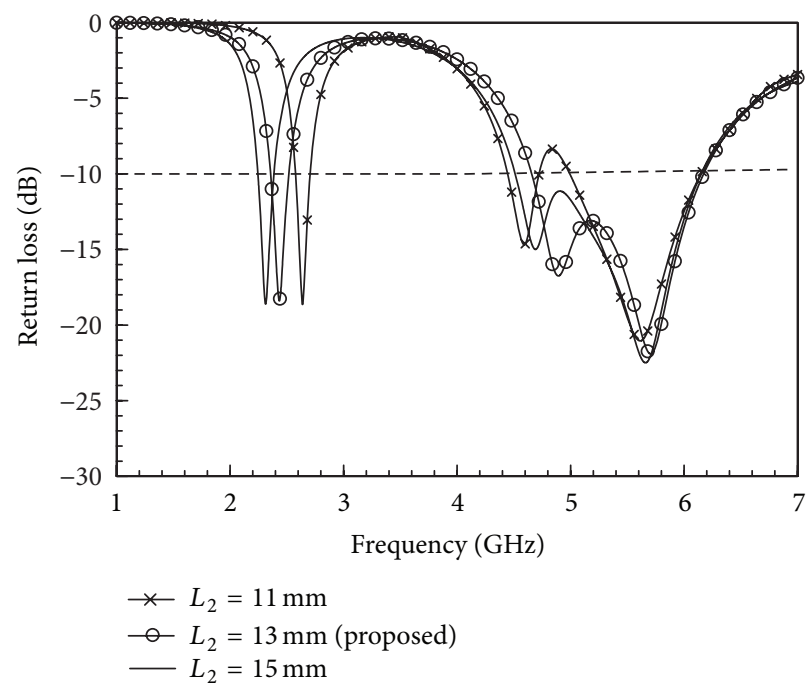

FIGURE 4: Simulated return loss versus frequency for various $L_{2} ; L_{1}$ is fixed as $7.5 \mathrm{~mm}$ and $H=3 \mathrm{~mm}$.

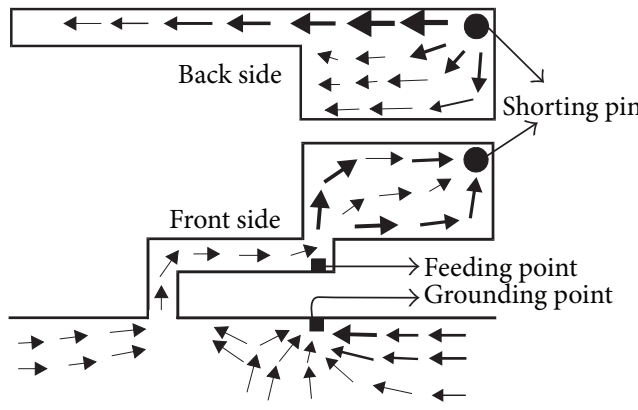

(a)

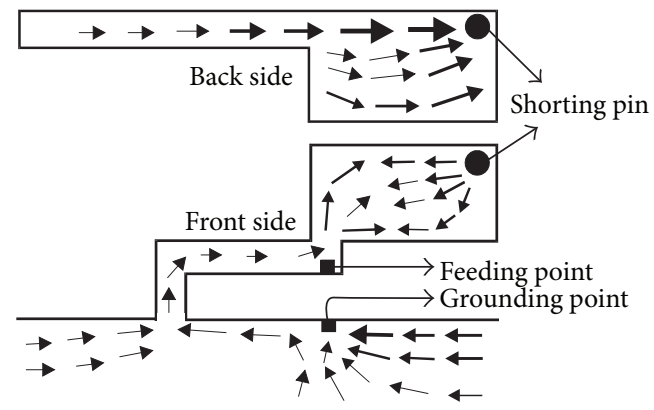

(b)

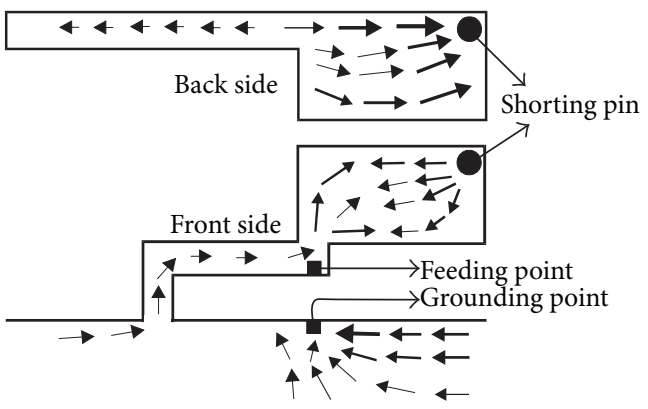

(c)

Figure 5: Simulated surface current distributions obtained at (a) 2.45, (b) 5.2, and (c) $5.8 \mathrm{GHz}$ for proposed FC-PIFA.

at higher frequency band. For the folded-coupling region of $H=1 \mathrm{~mm}$ and $L_{1}=7.5 \mathrm{~mm}$, the coupling effect generates a new resonant mode at around $5 \mathrm{GHz}$. However, it has a poor impedance matching. For further increasing the foldedcoupling region to $H=3 \mathrm{~mm}$ and $L_{1}=7.5 \mathrm{~mm}$, the impedance matching around $5 \mathrm{GHz}$ can be much improved. The $-10 \mathrm{~dB}$ bandwidths of the lower and upper bands reach about $159 \mathrm{MHz}(2358-2517 \mathrm{MHz}, 6.5 \%$ centered at $2.45 \mathrm{GHz})$ and $1512 \mathrm{MHz}(4658-6170 \mathrm{MHz}, 27.5 \%$ centered at $5.5 \mathrm{GHz})$, which are favorable for 2.4-GHz $(2400-2484 \mathrm{MHz})$ and $5-\mathrm{GHz}(5150-5825 \mathrm{MHz})$ WLAN communications. As expected, it exhibits a good agreement between the measured and the simulated results.

The influences of the parameters, the length of the foldedcoupled region $L_{1}$, and the back-side radiating strip $L_{2}$ are studied. Figure 3 shows the simulated return loss versus frequency for various $L_{1}$. With $L_{1}$ increasing from 6.5 to $8.5 \mathrm{~mm}$ and simultaneously the total length of $L_{1}$ and $L_{2}$ being fixed as $28 \mathrm{~mm}$, the upper band decreases gradually whereas the lower band changes slightly. This appearance indicates that the size of the folded-coupling region only affects the upper band. With further varying $L_{2}$ from 11 

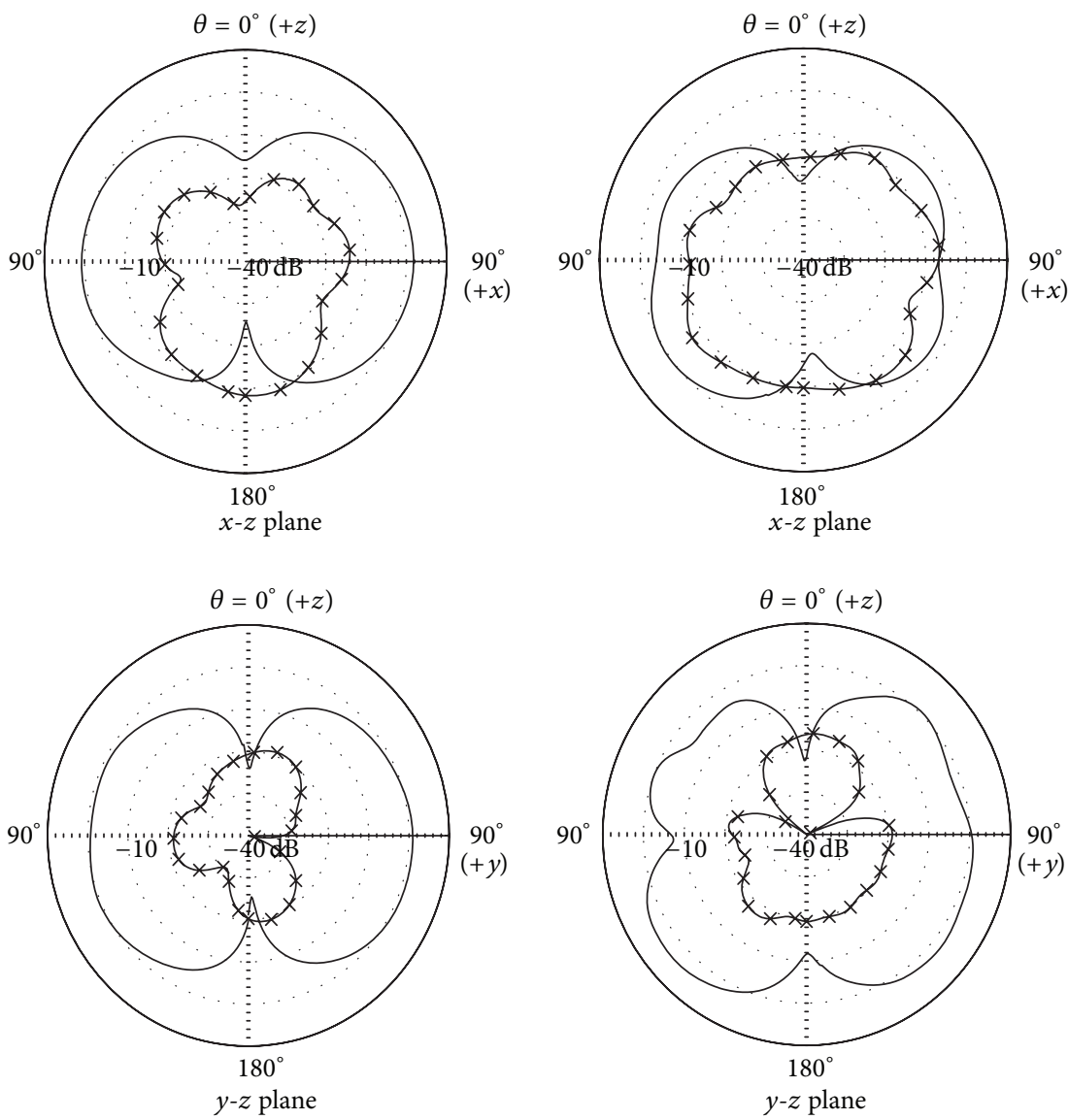

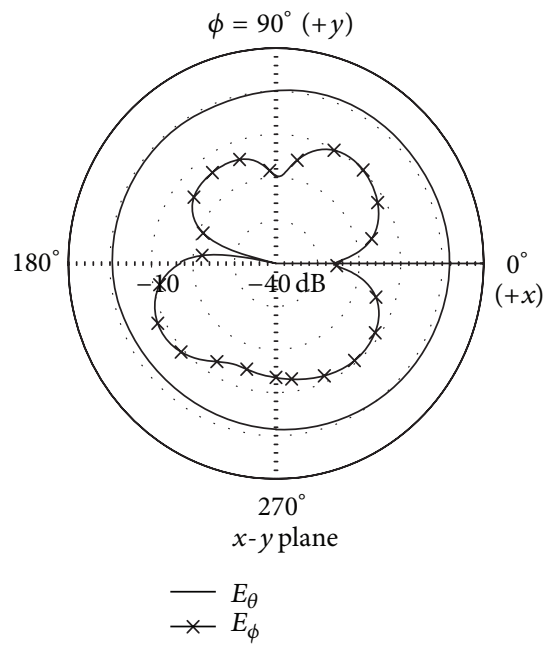

(a)

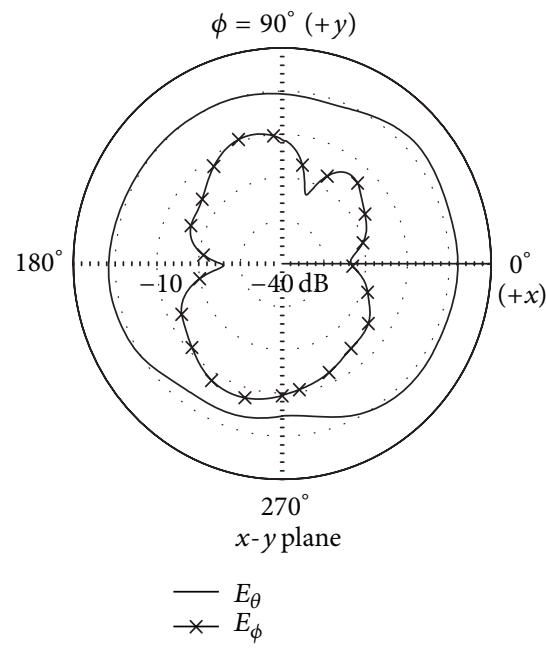

(b)

FiguRE 6: Measured radiation patterns of proposed FC-PIFA obtained at (a) 2.45 and (b) $5.5 \mathrm{GHz}$.

to $15 \mathrm{~mm}$ and simultaneously fixing the area of the foldedcoupling region $\left(H=3 \mathrm{~mm}\right.$ and $L_{1}=7.5 \mathrm{~mm}$ ), the lower band decreases gradually whereas the upper band changes slightly, as shown in Figure 4. This appearance demonstrates that the total length of the FC-PIFA dominates the resonant frequency of the lower band.
To explore the effect of folded-coupling technique in depth, Figures 5(a), 5(b), and 5(c) show the excited surface current distributions of the proposed FC-PIFA simulated via Ansoft HFSS at 2.45, 5.2, and 5.8 GHz, respectively. The main surface current path is observed from the feeding point to the open end of the radiating strip on the back side through the 

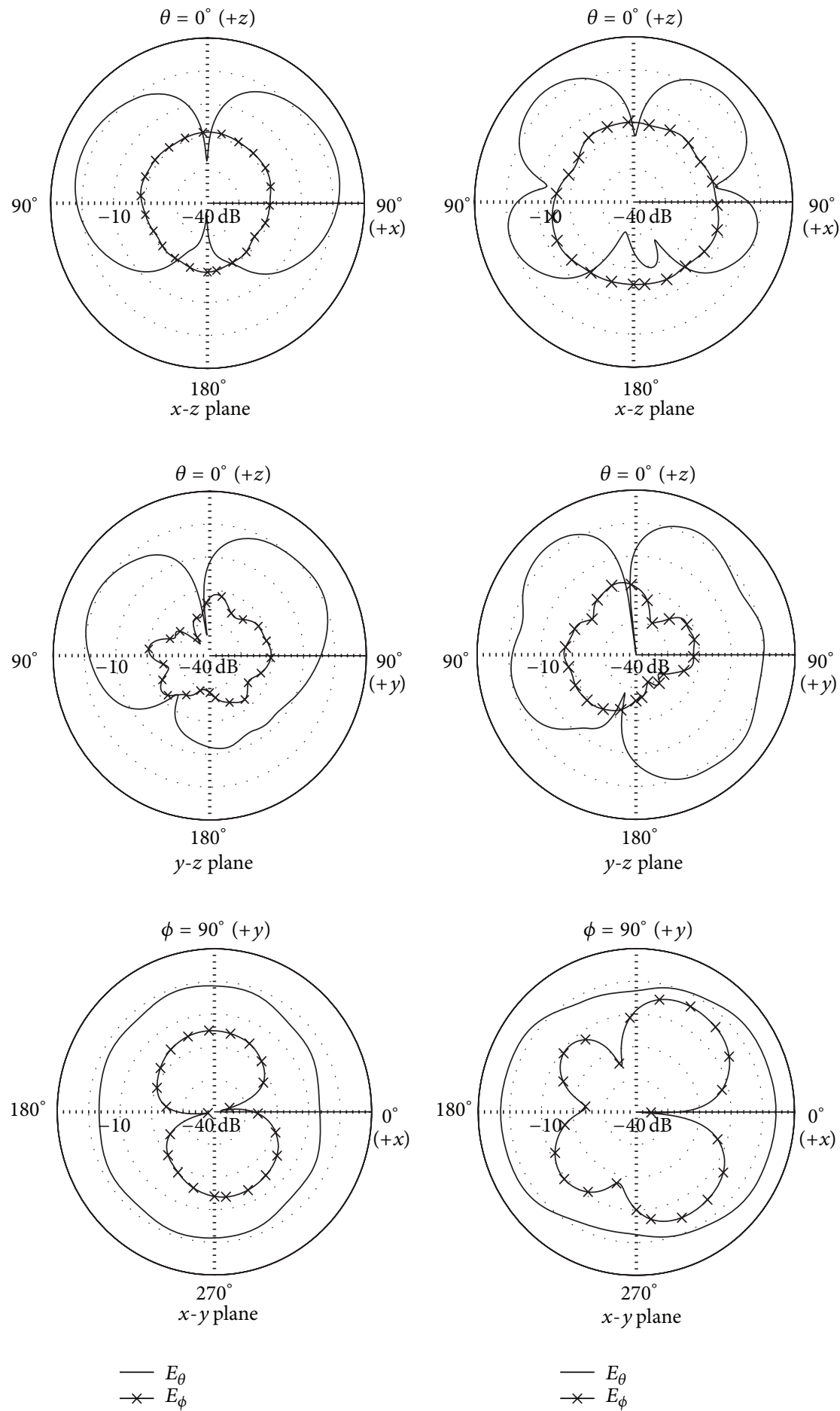

(a)

(b)

Figure 7: Simulated radiation patterns of proposed FC-PIFA obtained at (a) 2.45 and (b) $5.5 \mathrm{GHz}$.

shorting pin, as shown in Figure 5(a). The total length is about a quarter-wavelength corresponding to $2.45 \mathrm{GHz}$. In Figures $5(\mathrm{~b})$ and $5(\mathrm{c})$, the main surface current widely spread on the folded-coupling region, introducing two close resonant modes in $5 \mathrm{GHz}$ band. Of note, the main current path on the back radiating element at $5.8 \mathrm{GHz}$ is slightly shorter than that at $5.2 \mathrm{GHz}$, which interprets that two close but distinct resonant modes are induced owing to the folded-coupling technique.

Radiation characteristics of the proposed antenna are also studied. Figure 6 shows the measured radiation patterns at 2.45 and $5.5 \mathrm{GHz}$. Corresponding simulated radiation 


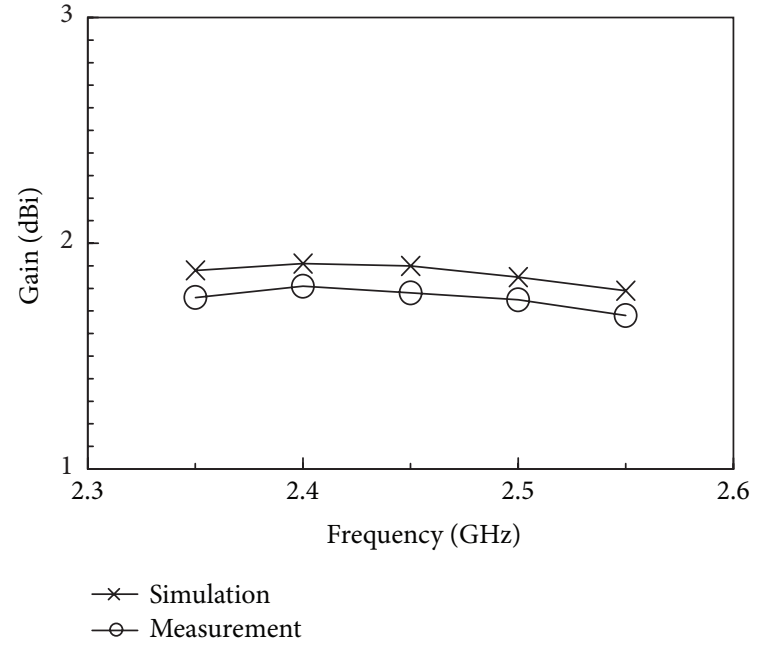

(a)

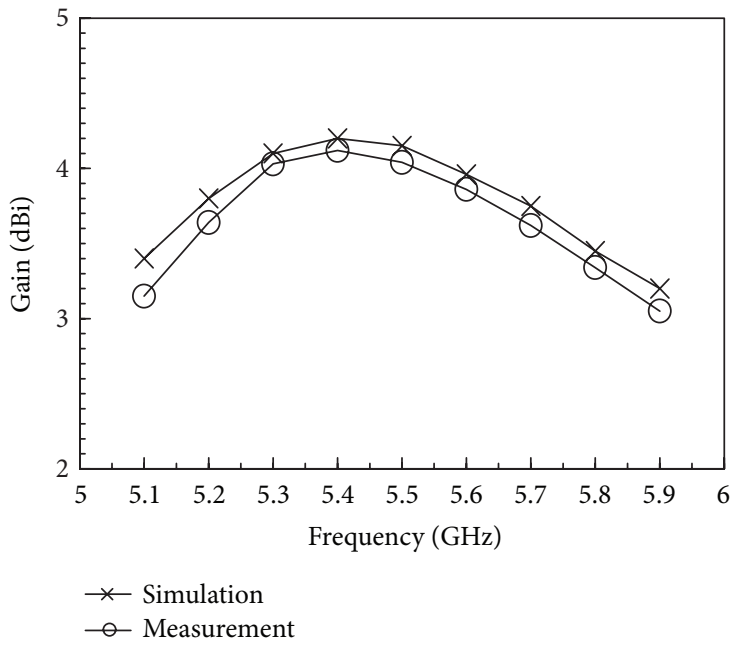

(b)

FIGURE 8: Simulated and measured antenna peak gain values versus frequency at (a) 2.35-2.55 and (b) 5.1-5.9 GHz of proposed FC-PIFA.

patterns are also shown in Figure 7 for comparison. The measurements generally consist with the simulations. For both operation frequencies in the $x-y$ plane (the azimuthal plane), the vertical component shows a relatively small variation and is close to omnidirection. This characteristic is favorable for WLAN application. Noticeably, a relatively stronger radiation in $+y$ plane can be ascribed to the shorting pin. Figure 8 shows the simulated and measured peak gain against frequency of the proposed FC-PIFA. For the lower band at $2.35-2.55 \mathrm{GHz}$, the measured gain varies in a range of 1.8-1.9 dBi. For the upper band at 5.1-5.9 GHz, the measured gain varies in a range of $3.0-4.1 \mathrm{dBi}$. The gain values within the whole operation bands are quite stable. The measured results are $0.1-0.2 \mathrm{dBi}$ lower than the simulations due to the attenuation caused by the $50 \Omega$ coaxial lines.

\section{Conclusion}

A dual-band FC-PIFA for WLAN communications has been successfully implemented. The prototype of the antenna has a low profile of $5 \mathrm{~mm}$ and occupies a small radiating area of $5 \mathrm{~mm} \times 20.5 \mathrm{~mm}$, which is easier to be embedded as an internal antenna in narrow space within the casing of a portable wireless device, such as a laptop or smart phone. By simply adjusting the folded-coupling region, two wide impedance bandwidths sufficient for $2.4 / 5 \mathrm{GHz}$ bands WLAN operation can be achieved easily. Good radiating performance and stable peak gain values can also be obtained, which is beneficial for challenging wireless propagation environments.

\section{Conflict of Interests}

The authors declare that there is no conflict of interests regarding the publication of this paper.

\section{References}

[1] Y. J. Cho, Y. S. Shin, and S. O. Park, "Internal PIFA for $2.4 / 5 \mathrm{GHz}$ WLAN applications," Electronics Letters, vol. 42, no. 1, pp. 8-9, 2006.

[2] C. T. Lee and K. L. Wong, "Uniplanar printed coupled-fed PIFA with a band-notching slit for WLAN/WiMAX operation in the laptop computer," IEEE Transactions on Antennas and Propagation, vol. 57, no. 4, pp. 1252-1258, 2009.

[3] M. Koubeissi, M. Mouhamadou, C. Decroze, D. Carsenat, and T. Monediere, "Triband compact antenna for multistandard terminals and users hand effect," International Journal of Antennas and Propagation, vol. 2009, Article ID 491262, 7 pages, 2009.

[4] S. Zuo, Y. Yin, Z. Zhang, and W. Wu, "A compact tri-band PIFA antenna for WLAN and WiMAX applications," Microwave and Optical Technology Letters, vol. 52, no. 4, pp. 919-922, 2010.

[5] C. Hu and Q. Zhu, "A compact wideband PIFA for dualband WLAN applications," in Proceedings of the International Conference on Microwave and Millimeter Wave Technology (ICMMT '12), vol. 4, pp. 1612-1615, May 2012.

[6] K. L. Wong and W. J. Chen, "Small-size microstrip-coupled printed PIFA for 2.4/5.2/5.8 GHz WLAN operation in the laptop computer," Microwave and Optical Technology Letters, vol. 51, no. 9, pp. 2072-2076, 2009.

[7] C. f. Tseng and Y. W. Chen, "Small PIFA for ZigBee and WLAN application," Microwave and Optical Technology Letters, vol. 55, no. 5, pp. 1074-1077, 2013. 

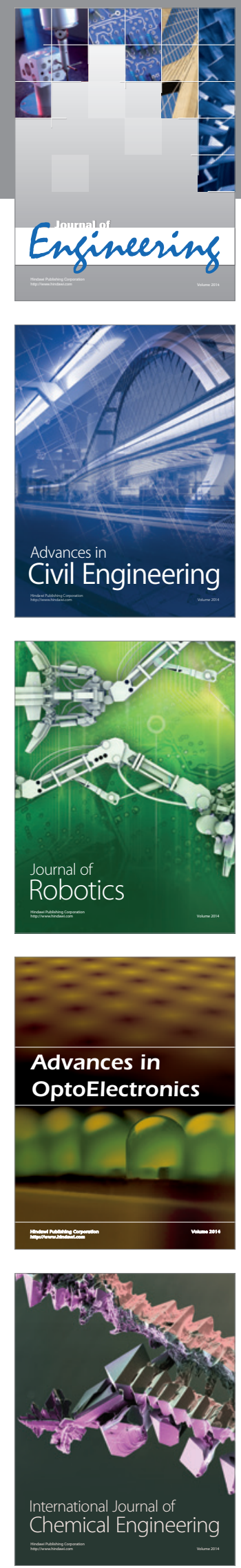

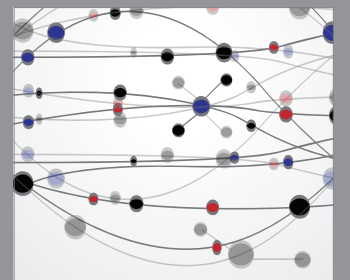

The Scientific World Journal
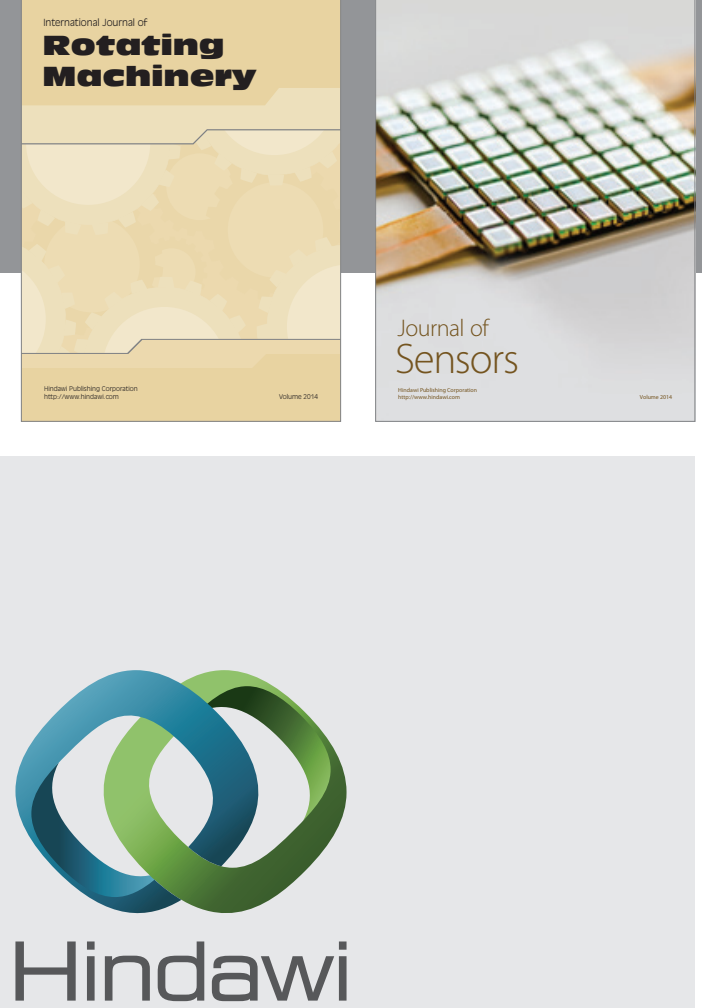

Submit your manuscripts at http://www.hindawi.com
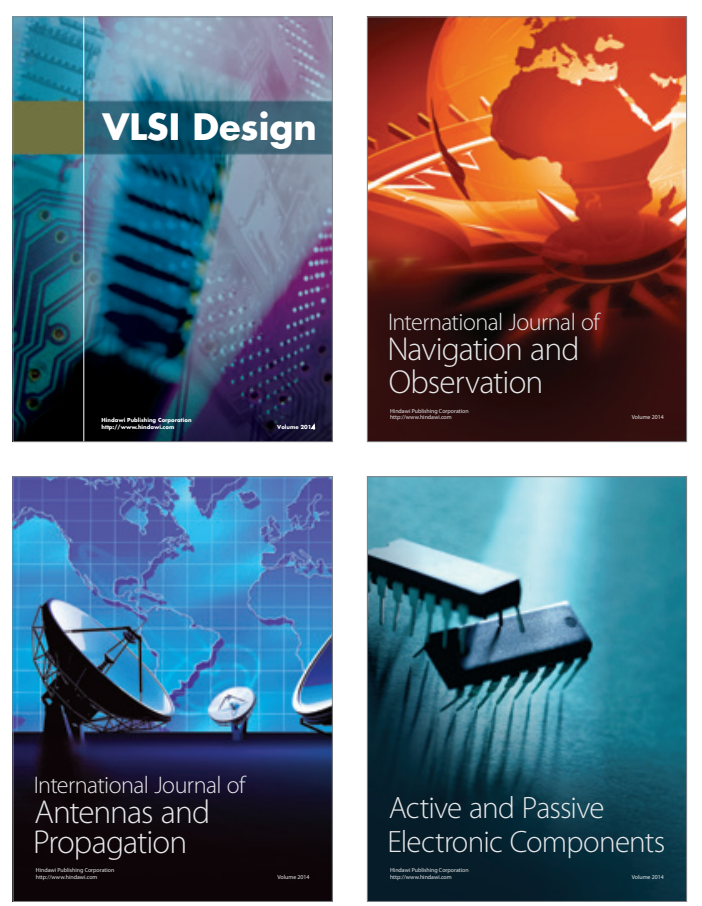
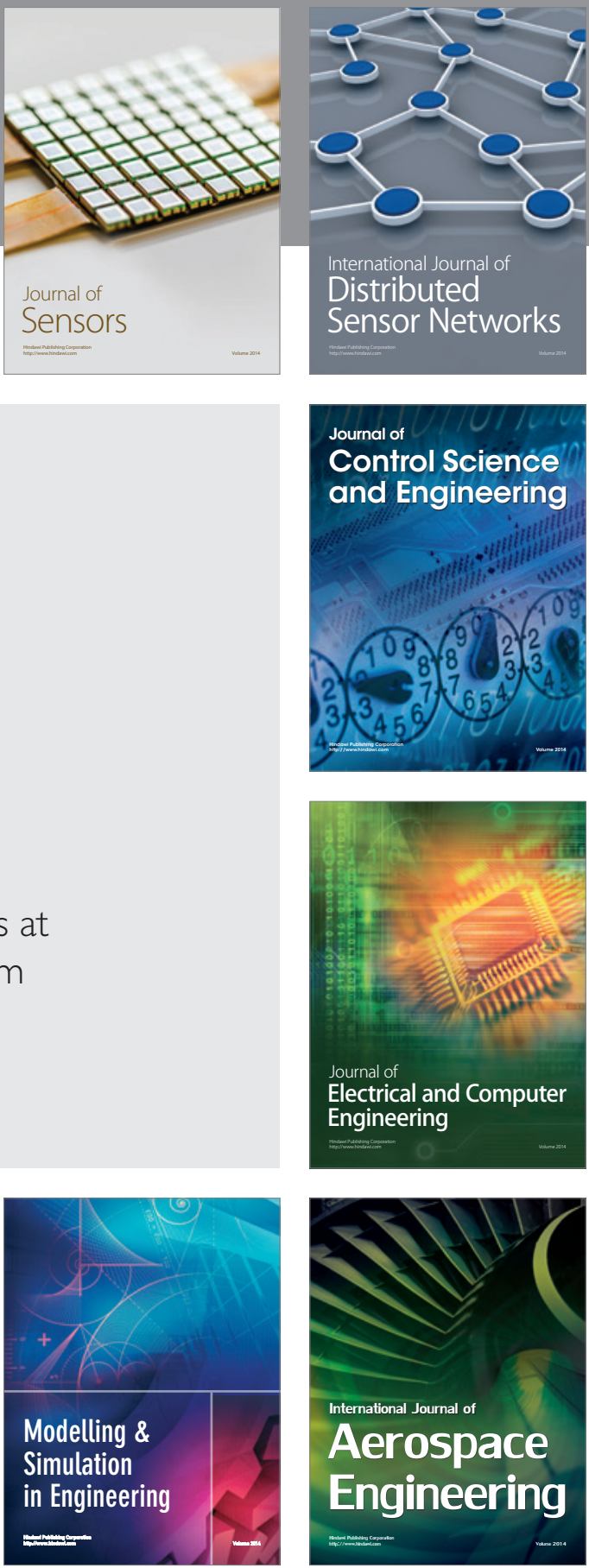

Journal of

Control Science

and Engineering
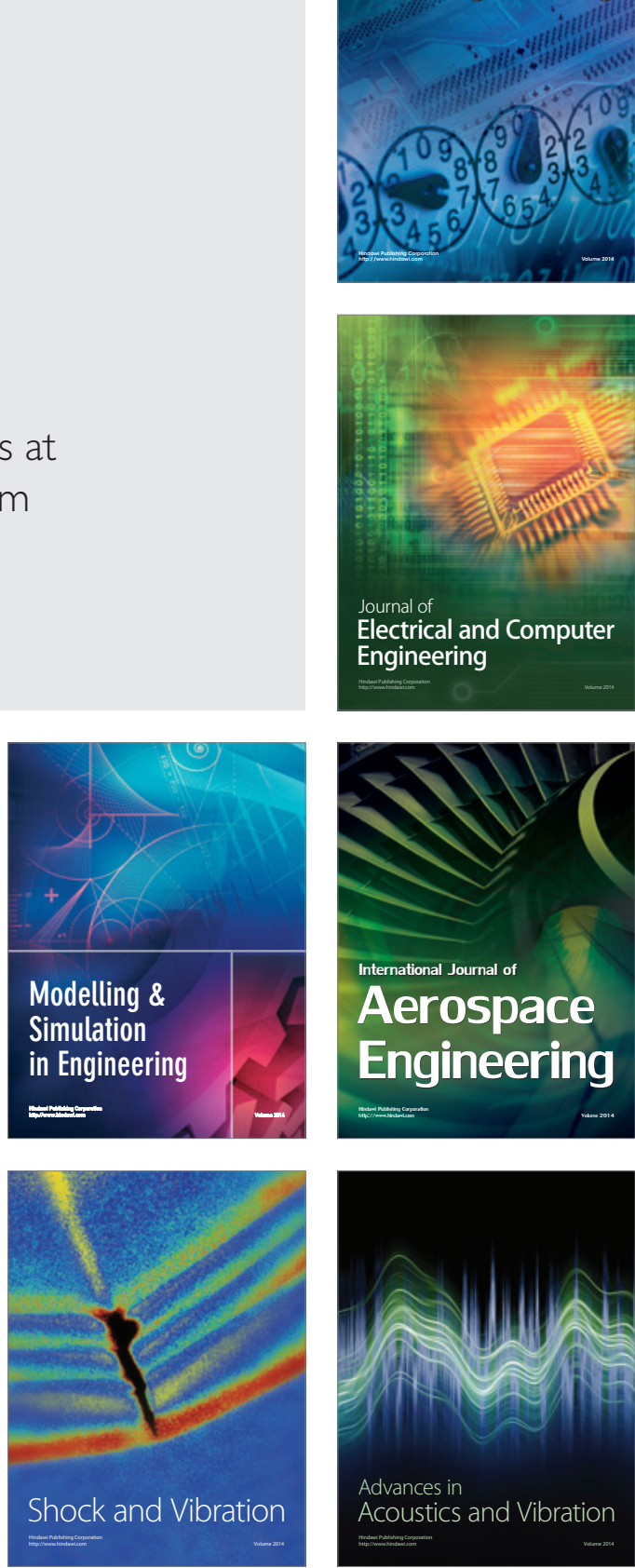